\title{
Sobrevivência de Bradyrhizobium japonicum em sementes de soja tratadas com fungicidas e os efeitos sobre a nodulação e a produtividade da cultura
}

\author{
Maira Rejane Costa ${ }^{1}$, Juliana Cristina Touro Cavalheiro ${ }^{2}$, Augusto César Pereira Goulart ${ }^{3}$, Fábio Martins Mercante ${ }^{3}$
}

${ }^{1}$ Bolsista da Embrapa Agropecuária Oeste, Caixa Postal 449, 79.804-970, Dourados, MS; ${ }^{2}$ Universidade Federal da Grande Dourados; ${ }^{3}$ Embrapa Agropecuária Oeste. Caixa Postal 449, 79.804-970, Dourados, MS

Autor para correspondência: Fábio Martins Mercante (fabio.mercante@embrapa.br)

Data de chegada: 01/04/2013. Aceito para publicação em: 05/08/2013.

\section{RESUMO}

Costa, M.R.; Cavalheiro, J.C.T.; Goulart, A.C.P.; Mercante, F.M. Sobrevivência de Bradyrhizobium japonicum em sementes de soja tratadas com fungicidas e os efeitos sobre a nodulação e a produtividade da cultura. Summa Phytopathologica, v.39, n.3, p.186-192, 2013.

A fim de garantir patamares mais elevados de fixação biológica de nitrogênio (FBN) e a sanidade das sementes de soja, o objetivo do estudo foi avaliar a influência da aplicação de diferentes fungicidas na sobrevivência de bactérias fixadoras de nitrogênio em sementes de soja e seus efeitos na nodulação das plantas e no rendimento de grãos da cultura. As avaliações de sobrevivência foram realizadas por meio do número mais provável-NMP (processo direto e indireto). Foram conduzidos ensaios sob condições de casa de vegetação, em vasos com terra não esterilizada e estudo a campo, num Latossolo Vermelho
Distrófico. Os resultados obtidos demonstraram que as estirpes de rizóbio podem ser afetadas por determinados fungicidas aplicados às sementes de soja. No estudo conduzido sob condições controladas de casa de vegetação com terra de mata nativa, verificou-se um efeito negativo da aplicação dos fungicidas, promovendo redução no número e na matéria seca dos nódulos. Na avaliação a campo, em solos com população estabelecida de Bradyrhizobium japonicum/B. elkanii, a nodulação e o rendimento de grãos da soja não foram afetados pelos diferentes fungicidas avaliados.

Palavras-chave adicionais: fixação biológica de nitrogênio, Glycine $\max$ (L.) Merril.

\section{ABSTRACT}

Costa, M.R.; Cavalheiro, J.C.T.; Goulart, A.C.P.; Mercante, F.M. Survival of Bradyrhizobium japonicum in soybean seeds treated with fungicides and the effects on nodulation and crop yield. Summa Phytopathologica, v.39, n.3, p.186-192, 2013.

To ensure higher levels of biological nitrogen fixation (BNF) and sanity of soybean seeds, the aim of this study was to evaluate the influence of application of different fungicides on the survival of nitrogen-fixing bacteria in soybean seeds and its effects on plant nodulation and crop grain yield. Survival evaluations were performed by using the most probable number-MPN (direct and indirect process). Experiments were carried out under greenhouse conditions in pots containing non-sterile soil, as well as under field conditions in clayey
Rhodic Hapludox. The obtained results showed that the rhizobium strains can be affected by certain fungicides applied to soybean seeds. In the study conducted under controlled greenhouse conditions with native forest soil, there was a negative effect of fungicide application, reducing the number and the dry matter of nodules. For the field evaluation, in soils with established population of Bradyrhizobium japonicum / B. elkanii, nodulation and yield of soybean grains were not affected by the different tested fungicides.

Additional keywords: biological nitrogen fixation, Glycine max (L.) Merril.

Nas últimas três décadas, o cultivo da soja (Glycine max (L.) Merril) foi o que mais cresceu no Brasil, representando $49 \%$ da área plantada de grãos no país (5). No Brasil, resultados de pesquisa demonstraram que as taxas de fixação biológica de nitrogênio (FBN) na soja podem exceder $300 \mathrm{~kg}$ de $\mathrm{N} \mathrm{ha}^{-1}$, o que representa $94 \%$ do total de nitrogênio total da planta (7). Tendo em vista a importância da cultura da soja para a economia brasileira, o uso de bactérias diazotróficas nos cultivos dessa leguminosa torna-se indispensável, uma vez que esses procariontes são capazes de promover a FBN, dispensando, assim, o uso de fertilizantes químicos nitrogenados, representando uma redução significativa de custos (18).

Contudo, além da importância do $\mathrm{N}$ para a produtividade de grãos de soja, outros procedimentos também são imprescindíveis, como escolha das sementes com padrão genético, físico, fisiológico e sanitário (16). Num momento inicial, a expansão da soja, aliada à ausência de cuidados fitossanitários, acarretou aumento na incidência de doenças nessa espécie. Segundo Goulart (13), a semente de soja tem um importante papel no estabelecimento da lavoura, além de ser o mais importante veículo de disseminação e sobrevivência de muitos patógenos. Cerca de quarenta doenças causadas por diversos organismos (fungos, bactérias, vírus e nematoides) podem afetar de forma negativa o estabelecimento das plantas no campo (25). Um grande número de microrganismos fitopatogênicos pode ser transmitido pelas sementes de soja, sendo o grupo dos fungos o mais numeroso. Desta forma, o tratamento de sementes com fungicidas é extremamente importante para reduzir os danos causados por patógenos associados 
às mesmas e também para proteger as sementes contra fungos de solo $(12,14)$. Atualmente, esta prática está amplamente difundida, sendo que mais de $90 \%$ das sementes de soja comercializadas no Brasil recebem esse tipo de tratamento (14).

A incompatibilidade entre o tratamento de sementes com determinados fungicidas e o uso de inoculantes tem sido considerada um dos maiores problemas relacionados à FBN na cultura da soja no País (7). Este fato se deve a diversos resultados de pesquisa mostrarem que, quando a inoculação é feita juntamente com o tratamento das sementes, mesmo que imediatamente após o envolvimento destas com os fungicidas, esta prática afeta a nodulação e a FBN, em diferentes graus, por reduzir a população de Bradyrhizobium spp. (2, 6, 17). A prática comum no tratamento de sementes, com combinações de fungicidas sistêmico e de contato, pode aumentar o potencial de toxicidade às bactérias presentes no inoculante $(7,17)$. Por outro lado, outros estudos não têm demonstrado estes efeitos negativos sobre a nodulação das plantas de soja, especialmente em condições de campo, com populações estabelecidas de Bradyrizhobium capazes de nodular a soja eficientemente $(12,15)$. Do ponto de vista molecular, Fabra et al. (11) e Dunfield et al. (10) relataram que determinados fungicidas podem causar alterações bioquímicas, influenciando as taxas de crescimento e propriedades simbióticas de Bradyrhizobium sp..

Considerando a importância da integração do tratamento de sementes de soja com fungicidas e a inoculação das sementes com o Bradyrhizobium japonicum/ B. elkanii,torna-se necessária a avaliação da compatibilidade destas duas práticas, de modo a garantir os patamares mais elevados de FBN e a sanidade das sementes. Assim, o objetivo do presente estudo foi avaliar os possíveis efeitos de toxicidade de diferentes fungicidas na sobrevivência das bactérias fixadoras de $\mathrm{N}_{2}$ nas sementes de soja e seus efeitos na nodulação das plantas e no rendimento de grãos da cultura.

\section{MATERIAL E MÉTODOS}

Os efeitos da aplicação dos fungicidas nas sementes de soja sobre a nodulação e fixação biológica de nitrogênio (FBN) foram avaliados em ensaio sob condições de casa de vegetação, em vasos com terra não esterilizada, e em campo com população estabelecida de Bradyrhizobium sp., com cerca de 6,3 x $10^{4}$ células/g de solo. Em ambas as avaliações, as sementes de soja, cultivar BRS 133, foram tratadas com diferentes fungicidas e, posteriormente, inoculadas com a mistura das estirpes SEMIA 5079 e SEMIA 5080 de Bradyrhizobium japonicum, na concentração de $6 \times 10^{9}$ células $\mathrm{g}^{-1}$ de inoculante turfoso, produzido pela Fundação Estadual de Pesquisa Agropecuária FEPAGRO (associada ao programa MIRCEN-Microbiological Resource Centre). Incluíram-se três tratamentos sem aplicação de fungicidas, sendo dois sem adição de inoculante (com e sem adubação mineral nitrogenada) e outro apenas inoculado com a mistura das estirpes.

Os fungicidas e doses do ingrediente ativo (g ou mL) para $100 \mathrm{~kg}$ de sementes utilizados no ensaio de avaliação da nodulação e FBN, em vasos com terra não esterilizada e na análise de sobrevivência das bactérias, em laboratório e sob condições casa de vegetação, foram os seguintes: fludioxonil + mefenoxam $(35+10$ para produto comercial A e 2,5 $+3,75$ para produto comercial B); carbendazim + thiram $(30$ +70 para os produtos comerciais A e B); L carboxin + thiram $(50+$ 50) e thiabendazole (50). Nos testes de sobrevivência dos rizóbios, em laboratório, adicionou-se, ainda, um tratamento com a aplicação de um fungicida com o princípio ativo fluquinconazole (50).
No ensaio a campo, foram avaliados os fungicidas, com as seguintes doses e ingredientes ativos $(\mathrm{g}$ ou $\mathrm{mL})$ : fludioxonil + mefenoxam $(2,5+$ 1,0 para o produto comercial A e $5+7,5$ para o produto comercial B); carbendazim + thiram $(30+70)$; carboxin + thiram $(50+50)$; fludioxonil (5); carbendazim (30); thiram (70) e carboxin (50).

\section{Sobrevivência das estirpes de Bradyrhizobium japonicum}

A estimativa do número de células de rizóbio em sementes de soja tratadas com os fungicidas e/ou inoculadas com a mistura das estirpes SEMIA 5079 e SEMIA 5080 de B. japonicum foi realizada por dois métodos baseados no número mais provável-NMP: a) diluição e contagem direta em placas (método de espalhamento); e b) diluição e infecção em plantas (processo indireto), utilizando-se a tabela adaptada de Andrade \& Hamakawa (1).

No método do NMP por espalhamento, a sobrevivência dos rizóbios foi avaliada em cinco momentos distintos: 0 (zero); 24; 48; 72 e 96 horas após a aplicação do inoculante microbiano nas sementes de soja, previamente tratadas com os fungicidas.

Inicialmente, uma amostra de $10 \mathrm{~g}$ das sementes de soja inoculada com a mistura das estirpes SEMIA 5079 e SEMIA 5080, na proporção de $500 \mathrm{~g}$ de inoculante/ $50 \mathrm{~kg}$ de semente, e tratadas com os diferentes fungicidas, foi colocada em enlernmeyers contendo $90 \mathrm{~mL}$ de água destilada esterilizada, sendo adicionados $300 \mu \mathrm{L}$ de Tween 80. Após a agitação, foram realizadas diluições sucessivas, sendo a contagem das bactérias avaliada nas concentrações $10^{-5}, 10^{-6} \mathrm{e} 10^{-7}$, em placas contendo meio de cultura agar-levedura-manitol-YMA (26). As placas com as diluições foram incubadas em estufa a $28^{\circ} \mathrm{C}$, pelo período de sete dias. A contagem das bactérias foi efetuada nas placas que apresentaram de 30 a 300 UFC (unidades formadoras de colônias).

No teste de infectividade dos rizóbios em soja, foram utilizadas três diluições $\left(10^{-2}, 10^{-3}\right.$ e $\left.10^{-4}\right)$, em ensaio conduzido em recipientes com substrato (areia + vermiculita, 1:1- v:v) esterilizado, sob condições de casa de vegetação. Antes do tratamento com os diferentes fungicidas e/ou inoculadas com os rizóbios, as sementes de soja foram desinfestadas superficialmente, sendo tratadas com álcool absoluto por 30 segundos e, em seguida, imersas em hipoclorito de sódio (10\%), por três minutos e lavadas 10 vezes com água destilada esterilizada (26). Cada semente recebeu a alíquota de $0,5 \mathrm{~mL}$ das diluições $10^{-2}$, $10^{-3}$ e $10^{-4}$. A estimativa do número de células foi realizada conforme Andrade \& Hamakawa (1). O delineamento experimental utilizado foi o de blocos ao acaso, com três repetições para cada diluição por tratamento. A avaliação foi realizada aos 30 dias após a semeadura.

\section{Nodulação e fixação biológica de nitrogênio em soja, sob condições controladas}

Para avaliação da aplicação de diferentes fungicidas em sementes de soja e seus efeitos na nodulação e fixação biológica do nitrogênio, foi conduzido um ensaio em condições de casa de vegetação, utilizandose vasos com terra proveniente de mata nativa da região de Dourados, MS. Foram utilizadas cinco sementes de soja, cv. BRS 133, em cada vaso, deixando-se duas plantas por vaso, após o desbaste. As plantas foram supridas com solução nutritiva isenta de nitrogênio (21), conforme descrito em Mercante (20). No tratamento controle com N, foi adicionado $1 \mathrm{~mL}$ de $\mathrm{NH}_{4} \mathrm{NO}_{3}$, duas vezes por semana, em quantidades suficientes para garantir a necessidade das mesmas. $\mathrm{O}$ delineamento experimental utilizado foi o de blocos ao acaso, com cinco repetições e nove tratamentos.

As avaliações da nodulação (número e massa seca de nódulos) e produção de massa seca da parte aérea foram realizadas aos quarenta e sete dias após o plantio. O delineamento experimental utilizado foi 
o de blocos ao acaso, com cinco repetições e nove tratamentos. Os dados foram submetidos à analise de variância, sendo as médias comparadas pelo teste de Tukey, a 5\% de probabilidade.

\section{Experimento a campo}

O ensaio a campo foi conduzido na safra 2004/2005, num Latossolo Vermelho distrófico, na área experimental da FAD/UNIDERP, Município de Dourados-MS $\left(22^{\circ} 16^{\circ} \mathrm{S}\right.$ e $\left.54^{\circ} 49^{\circ} \mathrm{W}\right)$. A adubação com fósforo $\left(\mathrm{P}_{2} \mathrm{O}_{5}\right)$ e potássio $\left(\mathrm{K}_{2} \mathrm{O}\right)$ foi realizada com base nos resultados da análise química do solo, sendo aplicados, em toda a área experimental, $300 \mathrm{~kg} \mathrm{ha}^{-1}$ da formulação 0-20-20. No tratamento-controle com N, foram aplicados $200 \mathrm{~kg} \mathrm{ha}^{-1}$ de ureia, sendo $50 \%$ na semeadura e $50 \%$ no florescimento. Cada parcela foi constituída de seis linhas com 5,0 $\mathrm{m}$ de comprimento, num espaçamento de $0,45 \mathrm{~m}$ entre linhas. $\mathrm{Na}$ avaliação de rendimento de grãos, foram consideradas duas linhas entre bordaduras, dispensando-se $0,5 \mathrm{~m}$ de cada extremidade. Utilizou-se o delineamento experimental em blocos casualizados, com seis repetições. Os dados foram submetidos à analise de variância, sendo as médias comparadas pelo teste de Tukey, a 5\% de probabilidade.

\section{RESULTADOS E DISCUSSÃO}

\section{Sobrevivência das estirpes de Bradyrhizobium japonicum}

Diluição e contagem direta em placas (método de espalhamento)

No primeiro momento (0 hora) após a inoculação dos rizóbios, verificou-se um maior número de células nos tratamentos sem uso de fungicidas, com inoculante padrão (IP) e no tratamento com aplicação do fungicida fluquinconazole, que apresentou valores similares aos do tratamento com IP (Tabela 1). Os demais fungicidas apresentaram valores semelhantes entre si, com menor número de células quantificadas, o que pode estar relacionado a um possível efeito de toxicidade dos produtos aos rizóbios. Numa avaliação com diferentes fungicidas, Campo et al. (7) observaram mortalidade em até $62 \%$ das bactérias em um período de duas horas após a inoculação das sementes tratadas com fungicidas, aumentando para $95 \%$ depois de 24 horas de contato. De acordo com Hungria \& Campo (17), os fungicidas aplicados nas sementes de soja podem afetar diretamente a sobrevivência do Bradyrhizobium, devido ao seu princípio ativo, $\mathrm{pH}$ e solventes usados nas formulações. Rennie et al. (23) destacaram que o efeito biotóxico de defensivos agrícolas à bactéria depende da dosagem do produto aplicado, dos isolados ou estirpes de bactérias presentes no inoculante, da metodologia de inoculação e das condições climáticas e do solo.

Nos períodos seguintes de contato do inoculante microbiano com os fungicidas (24; 48; 72 e 96 horas), verificou-se que as sementes de soja tratadas com a maioria dos produtos não apresentaram alterações no número de células dos rizóbios com o aumento do tempo de contato com o inoculante (Tabela 1). Do mesmo modo, Mercante et al. (20) observaram que a aplicação do fungicida fluquinconazole (doses $50 \mathrm{e}$ $58,3 \mathrm{~mL}$ do princípio ativo / $100 \mathrm{~kg}$ de sementes) em sementes de soja não afetou a sobrevivência das estirpes SEMIA 5079 e SEMIA 5080 de Bradyrhizobium japonicum, após 48 horas de contato com o inoculante.

Em alguns tratamentos, como na aplicação de carbendazim + thiram (produtos comerciais A e B), carboxin + thiram e thiabendazole, houve um acréscimo no número de células dos rizóbios, quando comparado ao momento inicial de contato ( 0 hora), conforme apresentado na Tabela 1. Resultado de estímulo no crescimento de células de Bradyrhizobium spp. (SEMIA 5019 e SEMIA 5079), com a aplicação de fungicida (thiabendazole + thiram) em sementes de soja, também foi verificado por Bueno et al. (6). Por outro lado, entre os fungicidas avaliados por Campo et al. (7), em testes de sobrevivência de Bradyrhizobium em sementes de soja, as combinações carbendazim + tolylfluanid e thiabendazole + tolylfluanid foram os que apresentaram redução maior que $20 \%$, em relação ao número de células.

De modo geral, os resultados de pesquisas da avaliação do efeito de fungicidas na sobrevivência de rizóbios são bastante inconsistentes, uma vez que estes estudos demonstram que os fungicidas podem afetar, de forma variável, a sobrevivência e nodulação de Bradyrhizobium em sementes de soja tratadas com fungicidas (4, 7, $22,24)$. Estes resultados demonstram claramente que o efeito dos ingredientes ativos na sobrevivência de células em organismos fixadores de nitrogênio não deve ser generalizado.

\section{Diluição e infecção em plantas (processo indireto)}

Os resultados de infectividade dos rizóbios inoculados em plantas de soja, nas diluições $10^{-2}, 10^{-3}$ e $10^{-4}$, demonstraram que os fungicidas avaliados não afetaram a sobrevivência das bactérias fixadoras de nitrogênio até a diluição de $10^{-4}$, uma vez que apresentaram valores similares ao do tratamento com inoculação padrão (IP), sem uso de fungicida (Tabela 2). De acordo com Campo et al. (7), a diminuição do efeito tóxico pode estar relacionada com a adsorção dos fungicidas na vermiculita presente no substrato utilizado nos vasos de Leonard.

Contudo, deve-se salientar que o tratamento com aplicação do fungicida carbendazim + thiram (produto comercial A) apresentou

Tabela 1. Sobrevivência ( $\mathrm{n}^{\circ}$ de células) de estirpes de Bradyrhizobium japonicum inoculadas em sementes de soja tratadas com fungicidas, avaliadas no momento da inoculação (0 hora) e após $24 ; 48 ; 72$ e 96 horas de contato.

\begin{tabular}{|c|c|c|c|c|c|}
\hline Tratamentos & 0 hora & 24 horas & 48 horas & 72 horas & 96 horas \\
\hline Fludioxonil + mefenoxam & $8,0 \times 10^{4}$ & $3,16 \times 10^{4}$ & $8,6 \times 10^{4}$ & $3,33 \times 10^{3}$ & $8,26 \times 10^{4}$ \\
\hline Fludioxonil + mefenoxam & $8,0 \times 10^{4}$ & $3,16 \times 10^{4}$ & $8,6 \times 10^{4}$ & $3,33 \times 10^{3}$ & $8,26 \times 10^{4}$ \\
\hline Carboxin + thiram + IP & $1,80 \times 10^{4}$ & $1,15 \times 10^{5}$ & $6,40 \times 10^{4}$ & $9,43 \times 10^{4}$ & $5,2 \times 10^{4}$ \\
\hline Thiabendazole + IP & $1,56 \times 10^{4}$ & $1,14 \times 10^{5}$ & $4,96 \times 10^{4}$ & $1,16 \times 10^{5}$ & $9,73 \times 10^{4}$ \\
\hline IP & $2,5 \times 10^{6}$ & $1,95 \times 10^{5}$ & $2,07 \times 10^{5}$ & $3,01 \times 10^{5}$ & $1,96 \times 10^{5}$ \\
\hline
\end{tabular}

*IP= inoculação padrão. Inoculante turfoso, aplicado na dose de $500 \mathrm{~g} / 50 \mathrm{~kg}$ de sementes, com solução açucarada a $10 \%$ como adesivo, e contendo $10^{9}$ células de Bradyrhizobium/ g de inoculante.

Médias seguidas pela mesma letra, nas colunas, não diferem estatisticamente pelo teste de Tukey, a 5\%. 
Tabela 2. Efeito da aplicação de fungicidas na sobrevivência de estirpes de Bradyrhizobium japonicum (SEMIA 5079 e SEMIA 5080), utilizando-se três concentrações distintas $\left(10^{-2}, 10^{-3}\right.$ e $\left.10^{-4}\right)$, pelo método de contagem do número mais provável (NMP).

\begin{tabular}{lcc}
\hline Tratamentos & Fator NMP & $\mathbf{N}^{0}$ de células de B. japonicum/ mL \\
\hline Fludioxonil + mefenoxam+ IP* & 109,849 & $1,09 \times 10^{4}$ \\
Fludioxonil + mefenoxam+ IP & 109,849 & $1,09 \times 10^{4}$ \\
Carbendazim + thiram (Produto A) + IP & 23,970 & $2,39 \times 10^{4}$ \\
Carboxin + thiram + IP & 109,849 & $1,09 \times 10^{4}$ \\
Thiabendazole + IP & 109,849 & $1,09 \times 10^{4}$ \\
Carbendazim + thiram ( Produto B) + IP & 109,849 & $1,09 \times 10^{4}$ \\
Fluquinconazole + IP & 109,849 & $1,09 \times 10^{4}$ \\
IP & 109,849 & $1,09 \times 10^{4}$ \\
Controle sem N & - & 0 \\
Controle com N & - & 0 \\
\hline *IP= inoculação padrão. Inoculante turfoso, aplicado na dose de 500 g/ 50 kg de sementes, com solução açucarada a $10 \%$ como adesivo, e contendo $10^{9}$ células de Bradyrhizobium/g de \\
inoculante. \\
Médias seguidas pela mesma letra, nas colunas, não diferem estatisticamente pelo teste de Tukey, a 5\%.
\end{tabular}

valores da concentração de células de rizóbios maiores que os demais tratamentos. Bikrol et al. (4) avaliaram diferentes concentrações do fungicida thiram em sementes de soja inoculadas com rizóbio (estirpe SB 119) e detectaram elevada toxicidade em relação aos fatores de crescimento de plantas e infecção de rizóbio, quando esse princípio ativo estava presente na concentração de $500 \mu \mathrm{g} / \mathrm{mL}$. Entretanto, quando presente na concentração de $100 \mu \mathrm{g} / \mathrm{mL}$ foi considerada ótima e eficiente para parâmetros de nodulação, peso de nódulos e atividade da nitrogenase. Puldeko \& Madrzac (22) avaliaram o efeito do fungicida Funaben (thiram $45 \%$ e carbendazim $20 \%$ ) na nodulação da soja inoculada com duas estirpes de Bradyrhizobium japonicum (USDA 110 e USDA 123) e verificaram uma redução da nodulação em tratamentos onde foram aplicados os fungicidas e fertilizantes nitrogenados de forma simultânea.

\section{Nodulação e fixação biológica de nitrogênio em soja}

No ensaio conduzido em vasos com terra proveniente de mata nativa, verificou-se um efeito negativo da aplicação dos fungicidas sobre a nodulação (número e massa de nódulos secos) das plantas de soja, quando comparado com plantas inoculadas com as estirpes de B. japonicum SEMIA 5079 e SEMIA 5080. A redução no número de nódulos variou de 24,7 (fludioxonil + mefenoxam - produto B) até $48,2 \%$ (carbendazim + thiram - produto A) em comparação com as plantas apenas inoculadas (Tabela 3). Quando comparado o número de nódulos das plantas inoculadas com aqueles produzidos quando os fungicidas fludioxonil + mefenoxam, produtos A e B, foram utilizados, observou-se uma variação na sua redução de 24,7 a $43,4 \%$, respectivamente. Do mesmo modo, estudos realizados por Revellin et al. (24) demonstraram efeito levemente tóxico do fungicida carboxin + thiram sobre a nodulação da soja, após $24 \mathrm{~h}$ de contato deste com estirpes de Bradyrhizobium japonicum, antes do plantio. Por outro lado, Bigaton et al. (3), em condições experimentais similares às do presente estudo, não verificaram decréscimos no número e peso de nódulos secos e na porcentagem de $\mathrm{N}$ foliar em plantas de soja, quando avaliados diferentes tratamentos com fungicidas.

Quanto à massa de nódulos secos, a redução variou entre 26,5 e $49,4 \%$, pela aplicação dos fungicidas carbendazim + thiram, e produtos comerciais B e A, respectivamente. Embora não tenham sido detectadas diferenças significativas $(p<0,05)$ na nodulação destas plantas tratadas com os diferentes produtos (A e B) formulados com os mesmos princípios ativos, deve-se considerar tais variações na redução da nodulação, indicando que, provavelmente, o efeito de toxicidade dos fungicidas não está relacionado apenas aos princípios ativos dos produtos, mas também com outros componentes da sua formulação. Do mesmo modo, Andrés et al. (2) verificaram decréscimos significativos no número e peso de nódulos secos de plantas de soja, quando utilizaram o tratamento de sementes com o fungicida thiram juntamente com uma estirpe de Bradyrhizobium sp., individualmente, e outra estirpe de inoculante comercial da Argentina, em casa de vegetação, sob condições estéreis. De acordo com Hungria \& Campo (17), a causa da redução na nodulação de plantas de soja pode estar relacionada à diminuição do número de células viáveis de $B$. japonicum e/ou alteração na composição de exsudatos liberados pelas raízes dessas plantas. Esta alteração nos exsudatos liberados pode alterar a sinalização molecular entre macros $\mathrm{e}$ microssimbiontes e, consequentemente, interferir no reconhecimento da bactéria à planta específica.

Por outro lado, Bueno et al. (6), avaliando o efeito dos fungicidas thiram, thiabendazole + thiram, metalaxyl, difenoconazole + thiram, carbendazim + thiram, fludioxonil + metalaxyl M, tiofanato metílico + tolyfluanid, thiabendazole e captan na sobrevivência de estirpes de Bradyrhizobium elkanii (SEMIA 5019) e Bradyrhizobium japonicum (SEMIA 5079), não evidenciaram qualquer redução na nodulação em plantas de soja, em casa de vegetação e em solo com população estabelecida de Bradyrhizobium. Resultados semelhantes foram encontrados por Cattelan et al. (9), que avaliaram, sob condições estéreis de casa de vegetação, os efeitos dos fungicidas captan, carboxin + thiram, thiabendazol, thiram, thiram + thiabendazol, pentacloronitrobenzeno + thiabendazol sobre quatro estirpes de Bradyrhizobium (SEMIA 5079, SEMIA 5080, SEMIA 587 e SEMIA 5019), com diferentes concentrações em inoculante turfoso; os autores não observaram efeitos negativos com a aplicação desses fungicidas, com exceção do captan, sobre o número de nódulos, massa de nódulos e teor de $\mathrm{N}$ no tecido foliar.

A produção de massa seca da parte aérea das plantas não foi afetada pela aplicação dos fungicidas nas sementes, quando comparada com o tratamento que recebeu apenas a inoculação das estirpes de rizóbio, sem aplicação de fungicidas (Tabela 3). Estudos realizados por Mercante et al. (19) corroboram os resultados obtidos no presente trabalho, em que a produção de massa seca da parte aérea de plantas de soja também não foi afetada por quaisquer dos fungicidas avaliados, em condições de casa de vegetação, utilizando- 
Tabela 3. Efeito da aplicação de fungicidas sobre a nodulação e produção de massa seca da parte aérea de plantas de soja, em condições de casa de vegetação, utilizando-se terra isento de bactérias fixadoras de $\mathrm{N}_{2}$.

\begin{tabular}{|c|c|c|c|c|c|}
\hline \multirow[t]{2}{*}{ Tratamento } & \multicolumn{2}{|c|}{ Nodulação } & \multicolumn{2}{|c|}{ Massa seca de nódulos } & \multirow{2}{*}{$\frac{\text { Massa seca da parte aérea }}{\left(\mathrm{g} \mathrm{planta}^{-1}\right)}$} \\
\hline & $\left(n^{0}\right.$ planta $\left.^{-1}\right)$ & Redução(\%) & $\left(\right.$ mg planta $\left.{ }^{1}\right)$ & Redução (\%) & \\
\hline Fludioxonil + mefenoxam $\left(\right.$ Produto A) $+\mathrm{IP}^{*}$ & $14,2 \mathrm{bc}$ & 43,4 & $18,8 \mathrm{~b}$ & 44,0 & 0,76 a \\
\hline Fludioxonil + mefenoxam $($ Produto $\mathrm{B})+$ IP & $18,9 \mathrm{~b}$ & 24,7 & $23,8 \mathrm{~b}$ & 29,2 & 0,94 a \\
\hline Carbendazin + thiram $($ Produto $\mathrm{A})+\mathrm{IP}$ & $13,0 \mathrm{c}$ & 48,2 & $17,0 \mathrm{~b}$ & 49,4 & 0,88 a \\
\hline Carboxin + thiram + IP & $14,2 \mathrm{bc}$ & 43,4 & $18,7 \mathrm{~b}$ & 44,3 & 0,81 a \\
\hline Thiabendazole + IP & $15,2 \mathrm{bc}$ & 39,4 & $21,5 \mathrm{~b}$ & 36,0 & $0,69 \mathrm{ab}$ \\
\hline Carbendazin + thiram $($ Produto B $)+$ IP & $17,2 \mathrm{bc}$ & 31,5 & $24,7 \mathrm{~b}$ & 26,5 & 0,86 a \\
\hline IP & $25,1 \mathrm{a}$ & 0 & 33,6 a & 0 & 0,86 a \\
\hline Controle sem $\mathrm{N}$ & $1,2 \mathrm{~d}$ & - & $1,61 \mathrm{c}$ & - & $0,47 \mathrm{~b}$ \\
\hline Controle com $\mathrm{N}$ & $0,4 \mathrm{~d}$ & - & $0,5 \mathrm{c}$ & - & $0,86 \mathrm{a}$ \\
\hline CV (\%) & 20,1 & & 22,2 & & 16,8 \\
\hline
\end{tabular}

*IP= inoculação padrão. Inoculante turfoso, aplicado na dose de $500 \mathrm{~g} / 50 \mathrm{~kg}$ de sementes, com solução açucarada a $10 \%$ como adesivo, e contendo $10^{9}$ células de Bradyrhizobium/ g de inoculante.

Médias seguidas pela mesma letra, nas colunas, não diferem estatisticamente pelo teste de Tukey, a 5\%.

Tabela 4. Efeitos da aplicação de fungicidas sobre a nodulação, produção de massa seca da parte aérea, teores de $\mathrm{N}$ nas folhas e grãos de plantas de soja e

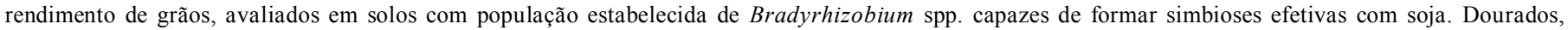
MS.

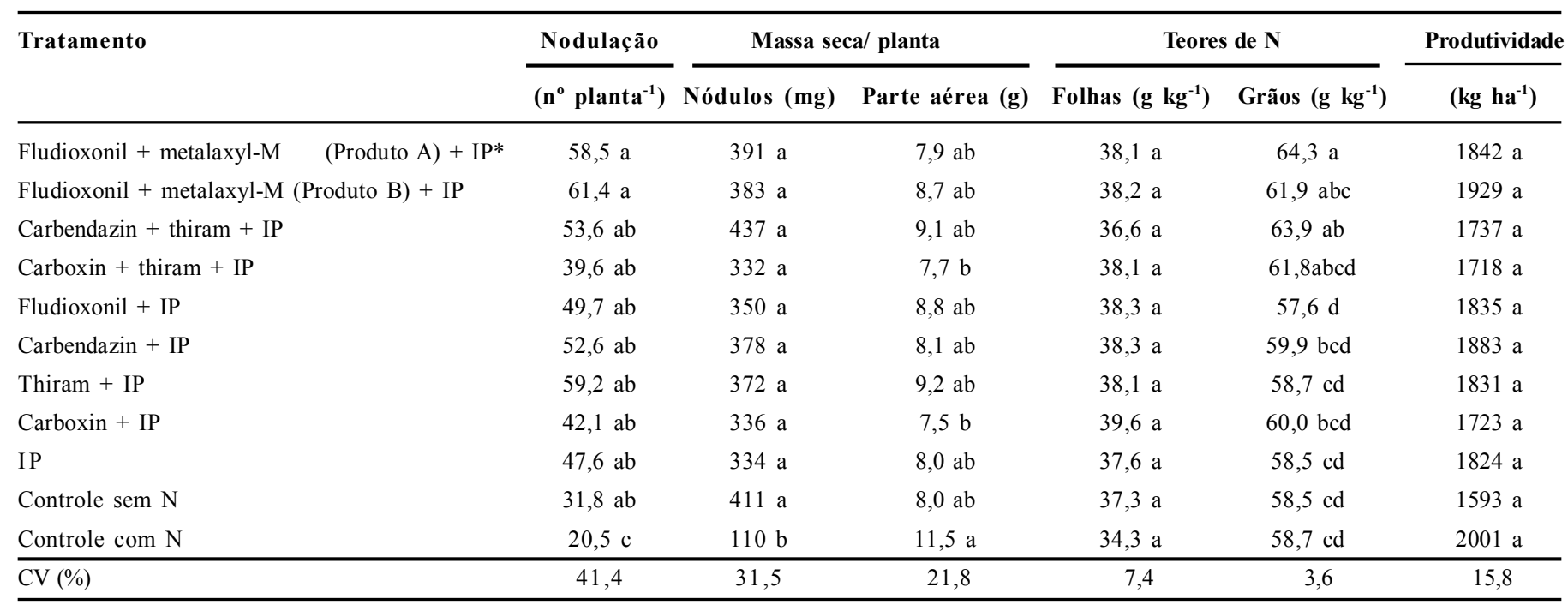

*IP= inoculação padrão. Inoculante turfoso, aplicado na dose de $500 \mathrm{~g} / 50 \mathrm{~kg}$ de sementes, com solução açucarada a $10 \%$ como adesivo, e contendo $10^{9}$ células de Bradyrhizobium/ g de inoculante.

Médias seguidas pela mesma letra, nas colunas, não diferem estatisticamente pelo teste de Tukey, a 5\%.

se substrato esterilizado (areia:vermiculita; 1:1).

Resultados em campo com população de Bradyrhizobium sp.

No ensaio conduzido a campo, em solo com população estabelecida de Bradyrhizobium japonicum e/ou B. elkanii, na ordem de 6,3 x 10 células/g de solo, não foram detectados efeitos negativos nas variáveis avaliadas com a aplicação de fungicidas nas sementes, independentemente do produto utilizado (Tabela 4). Destaca-se que a aplicação de fludioxonil + metalaxyl-M e de carbendazim + thiram proporcionou teores de $\mathrm{N}$ nos grãos de soja superiores aos verificados no tratamento apenas inoculado (sem fungicida). Os resultados obtidos neste estudo indicam a possibilidade de compatibilização do tratamento de sementes de soja com determinados fungicidas e a inoculação das sementes com bactérias fixadoras de $\mathrm{N}_{2}$, em solos com população estabelecida de B. japonicum e/ou B. elkanii.

Por outro lado, em solos de primeiro ano de cultivo de soja, onde não havia uma população estabelecida de Bradyrhizobium japonicum e ou B. elkanii, Campos \& Hungria (17) destacaram maior frequência de efeitos negativos. Do mesmo modo, Pudelko \& Madrzack (22) observaram que o fungicida funabenT utilizado no tratamento de sementes na cultura de soja, em solos sem população estabelecida de Bradyrhizobium sp., reduziu significativamente o número e tamanho de nódulos, bem como a distribuição dos nódulos na raiz da planta.

Resultados obtidos por Campo et al. (7), quando avaliaram a compatibilidade entre sementes tratadas com fungicidas e inoculadas com Bradyrhizobium em áreas experimentais caracterizadas com ausência e presença de Bradyrhizobium, demonstraram que, de modo geral, as misturas de fungicidas reduziram a nodulação em 14\% (áreas 
com população estabelecida), 33\% (áreas sem população estabelecida, caracterizada com solo do tipo argiloso) e 73\% (áreas sem população estabelecida, caracterizada com solo do tipo arenoso). Estudos conduzidos por Revellin et al. (24), sob condições de campo, num solo calcário na França, demonstraram que, embora o fungicida carboxin + thiram tenha reduzido significativamente o número e peso de nódulos de plantas de soja, a produtividade não foi afetada.

Deve-se salientar que, em solos de primeiro ano de cultivo de soja, os microssimbiontes capazes de nodular e fixar o $\mathrm{N}_{2}$ nesta leguminosa não estão presentes no solo e, havendo toxicidade provocada por qualquer componente do fungicida utilizado, poderia ocorrer uma redução na nodulação das raízes e, consequentemente, menor eficiência do processo de fixação biológica de nitrogênio. Neste sentido, para minimizar os danos causados por determinados fungicidas sobre os rizóbios e, consequentemente, frustração de produtividade de grãos nas lavouras, devido à indisponibilidade de $\mathrm{N}$ em quantidades suficientes para obtenção de altos rendimentos e/ou perdas significativas pela ausência do tratamento das sementes de soja com fungicidas, tem sido sugerida a utilização de doses mais elevadas de inoculante microbiano para áreas de primeiro cultivo de soja $(25,17)$. Além disso, tem sido demonstrado que a inoculação no sulco de semeadura, por aspersão, diminui o efeito deletério dos tratamentos das sementes (8), representando uma alternativa ao tratamento tradicional de inoculação nas sementes.

\section{REFERÊNCIAS BIBLIOGRÁFICAS}

1. ANDRADE, D. S.; HAMAKAWA, P. J. Estimativa do número de células viáveis de rizóbio no solo e em inoculantes por infecção em plantas. In: HUNGRIA, M.; ARAUJO, R. S. (Ed.). Manual de métodos empregados em estudos de microbiologia agrícola. Brasília, DF: EMBRAPA-SPI, 1994. p. 63-94.

2. ANDRÉS, J. A.; CORREA, N. S.; ROSAS, S. B. Survival and symbiotic properties of Bradyrhizobium japonicum in the presence of thiram: isolation of fungicide resistant strains. Biology and Fertility of Soils, Berlin, v. 26, n. 2, p. 141-145, 1998.

3. BIGATON, D.; BACCHI, L. M. A.; MERCANTE, F. M.; GAVASSONI, W. L. Fungicidas aplicados em tratamento de sementes de soja e seus efeitos sobre a nodulação e a fixação biológica de nitrogênio. Revista Agricultura Tropical, Cuiabá, v. 9, s/p, 2006/2007.

4. BIKROL, A.; SAXENA, N.; SINGH, K. Response of Glycine max in relation to nitrogen fixation as influenced by fungicide seed treatment. African Journal of Biotechnology, Grahamstown, v. 4, n. 7, p. 667-671, 2005.

5. BRASIL. Ministério da Agricultura, Pecuária e Abastecimento. Soja. Brasília, DF, [2012?]. Disponível em: <http:// www.agricultura.gov.br/vegetal/culturas/soja $>$. Acesso em: 2 out. 2012.

6. BUENO, C. J.; MEYER, M. C.; SOUZA, N. L. Efeito de fungicidas na sobrevivência de Bradyrhizobium japonicum (SEMIA 5019 e SEMIA 5079) e na nodulação da soja. Acta Scientiarum: agronomy, Maringá,v. 25, n. 1, p. 231-235, 2003.

7. CAMPO, R. J.; ARAUJO, R. S.; HUNGRIA, M. Nitrogen fixation with the soybean crop in Brazil: compatibility between seed treatmente with fungicides and bradyrhizobial inoculants. Symbiosis, Philadelphia, v. 48, n. 1/3, p. 154-163, 2009.

8. CAMPO, R. J.; ARAUJO, R. S.; MOSTASSO, F. L.; HUNGRIA, M. Inoculação no sulco de plantio da soja como alternativa para o tratamento de semente com fungicidas e micronutrientes. Revista Brasileira de Ciência do Solo, Viçosa, MG, v. 34, n. 4, p. 1103-1112, 2010.

9. CATtelan, A. J.; SPOlADORI, C. L.; HenNing, A. A. Efeito do tratamento de sementes de soja com fungicidas recomendados sobre a fixação do nitrogênio atmosférico e a sobrevivência do Bradyrhizobium japonicum em casa de vegetação. In: SIMPÓSIO BRASILEIRO SOBRE MICROBIOLOGIA DO SOLO, 3.; REUNIÃO DE LABORATÓRIOS PARA RECOMENDAÇÃO DE ESTIRPES DE RHIZOBIUM E BRADYRHIZOBIUM, 6., 1994, Londrina. Microbiologia do solo: desafios para o século XXI: anais. Londrina: IAPAR, 1995. p. 399-403.

10. DUNFIELD, K. E.; SiCILIANO, S. D.; GERMIDA, J. J. The fungicides thiram and captan affect the phenotypic characteristics of Rhizobium leguminosarum strain $\mathrm{C} 1$ as determined by FAME and Biolog analyses. Biology and Fertility of Soils, Berlin, v. 31, n. 3/4, p. 303-309, 2000.

11. FABRA, A.; ANGELINI, J.; DONOLO, A.; PERMIGIANI, M.; CASTRO, S. Biochemical alterations in Bradyrhizobium sp. USDA 3187 induced by the fungicide Mancozeb. Antonie van Leeuwenhoek, Amsterdam, v. 73, n. 3, p. 223-228, 1998.

12. GIANASI, L.; FERNANDES, N.; LOURENÇO, A. S. Fungicidas aplicados em tratamentos de sementes de soja e seus efeitos sobre a nodulação, fixação de nitrogênio, produção de matéria seca e produtividade. Summa Phytopathologica, Jaboticabal, v. 26, n. 3 , p. $352-355,2000$.

13. GOULART, A. C. P. Fungos em sementes de soja: deteç̧ão, importância e controle. Dourados: Embrapa Agropecuária Oeste, 2005. 72 p.

14. GOUlart, A. C. P. Tratamento de sementes de soja com fungicidas. In: CONGRESO DE LA SOJA DEL MERCOSUR, 5.; FORO DE LA SOJA ASIA-MERCOSUR, 1., 2011, Rosario. Un grano: un universo. Disponível em: <http:// www.mercosoja2011.com.ar/site/wp-content/imagenes/ GOULART-Augusto1.pdf $>$. Acesso em: 10 de dezembro de 2012

15. GUPTA, S. B.; RAWAT, A. K.; KHARE, A. K. Effect of pre and post inoculation seed treatment with fungicides on nodulation and grain yield of soyabean. Legume Research, Haryana, v. 11, n. 4, p. 167-172, 1988.

16. Henning, A. A. Patologia e tratamento de sementes: noções gerais. Londrina: Embrapa Soja, 2004. 51 p. (Embrapa Soja. Documentos, 235).

17. HUngRia, M.; CAMPO, R. J. Compatibilidade de uso de inoculantes e fungicidas no tratamento de sementes de soja. Londrina: Embrapa Soja, 2000. 11 p. (Embrapa Soja. Circular técnica, 26).

18. HUNGRIA, M.; CAMPO, R. J.; MENDES, I. A importância do processo de fixação biológica do nitrogênio para a cultura da soja: componente essencial para a competitividade do produto brasileiro. Londrina: Embrapa Soja; Planaltina, DF: Embrapa Cerrados. 80 p. (Embrapa Soja. Documentos, 283).

19. MERCANTE, F. M. Diversidade genética de rizóbio que nodula o feijoeiro e troca de sinais moleculares na simbiose com plantas hospedeiras. 1997. 199 p. Tese (Doutorado) - Universidade Federal Rural do Rio de Janeiro, Rio de Janeiro.

20. MERCANTE, F. M.; COSTA, M. R.; KAWSKI, N. L.; TARASIUK, V. A.; GOULART, A. C. P. Sobrevivência de Bradyrhizobium spp. em sementes de soja tratadas com fungicidas e seus efeitos na nodulação das plantas. In: CONGRESSO BRASILEIRO DE CIÊNCIA DO SOLO, 31 ., 2007, Gramado. Conquistas e desafios para a ciência do solo brasileira: livro de resumos. Porto Alegre: SBCS, Núcleo Regional Sul, 2007. p. 33.

21. NORRIS, D. O.; T'MANNETJE, L.The symbiotic specialization of African Trifolium spp. in relation to their taxonomy and their agronomic use. East African Agricultural and Forestry Journal, Nairobi, v. 29, n. 3, p. 214-35, 1964.

22. PULDEKO, K.; MADRZAK, C. J. Influence of fungicide Funaben on nodulation of soybean in the field conditions. Journal of Plant Protection Research, Oxford, v. 44, $\mathrm{n}$. 2, p. 155-159, 2004.

23. RENNIE, R. J.; HOWARD, R. J.; SWANSON, T. A.; FLORES, 
G. H. A. The effect of seed applied pesticides on growth and $\mathrm{N}$ fixation in pea, lentil and fababean. Canadian Journal of Plant Science, Ottawa, v. 65, n. 1, p. 23-38, 1985.

24. REVELlin, C.; LETERME, P.; CATROUX, G. Effect of some fungicide seed treatment on the survival of Bradyrhizobium japonicum and on nodulation and yield of soybean [Glycine max (L.) Merril]. Biology and Fertility of Soils, Berlin, v. 16, p.211-214, 1993.

25. TECNOLOGIAS de produção de soja - Região Central do Brasil 2012 e 2013. Londrina: Embrapa Soja, 2011. 261 p. (Embrapa Soja. Sistemas de produção, 15).

26. VINCENT, J. M. A manual for the practical study or rootnodule bactéria. London: International Biological Programme, 1970. p. 3-4. 